\title{
TRENDS IN ACTIVE COMMUTING TO SCHOOL AMONG CZECH SCHOOLCHILDREN FROM 2006 TO 2014
}

\author{
Jan Pavelka1, Dagmar Sigmundová', Zdeněk Hamřík², Michal Kalman', Erik Sigmund', Frida Mathisen ${ }^{3}$ \\ ${ }^{1}$ Institute of Active Lifestyle, Faculty of Physical Culture, Palacký University Olomouc, Olomouc, Czech Republic \\ ${ }^{2}$ Department of Recreation and Leisure Studies, Faculty of Physical Culture, Palacký University Olomouc, Olomouc, Czech Republic \\ ${ }^{3}$ Department of Health Promotion and Development, Faculty of Psychology, University of Bergen, Bergen, Norway
}

\section{SUMMARY}

Objective: Active commuting (AC) is an important factor in increasing the total daily physical activity (PA) in children, which is significant for their health and positive physical behaviour in adulthood. The objective of the study was to describe trends in active commuting to school among Czech girls and boys aged 11-15 years from 2006 to 2014, using data from the Health Behaviour in School-aged Children (HBSC) study.

Methods: To investigate trends in AC among Czech children of school age data obtained from the HBSC surveys carried out in 2006, 2010, and 2014 was used. The study sample comprised 12,273 respondents, out of whom 5,992 (48.8\%) were boys and 6,281 (51.2\%) girls. The overall trends in $\mathrm{AC}$ were evaluated using logistic regression analysis.

Results: Compared with 2006, there was an overall decrease in AC among the 13-year-old boys and 13-year-old girls (boys - 71.8\% in 2006 to $50.1 \%$ in 2014, girls $-69.3 \%$ in 2006 to $46.3 \%$ in 2014). The proportion of children AC (walking and cycling) to school significantly decreased from $74.3 \%$ in 2006 to $53.4 \%$ in 2014.

Conclusion: This study demonstrated that AC to school decreased sharply among Czech children of school age from 2006 to 2014. However, walking was the most frequently used mode of travel. The boys were significantly more likely to cycle to school compared to the girls. PA interventions for youth should encourage participation in AC to school in the Czech Republic.

Key words: trends, active commuting, physical activity, HBSC

Address for correspondence: J. Pavelka, Faculty of Physical Culture, Palacký University Olomouc, trída Míru 111, 77111 Olomouc, Czech Republic. E-mail: jan.pavelka@upol.cz

https://doi.org/10.21101/cejph.a5095

\section{INTRODUCTION}

Active commuting (AC) is most often defined as walking, cycling, or other human-powered modes of transport (in-line skating, skateboarding) used for the practical purpose of getting from one place to another in everyday life (1). AC is also perceived as an easy and effective tool to increase the level of daily PA among school-aged children $(2,3)$. Active commuting to school was independently associated with greater levels of PA and lower levels of body fatness and obesity in adolescents. However, further research, especially longitudinal or trendrelated studies, is necessary in order to better quantify these relationships (4). Generally, as a result of the global decline in PA and an increase in sedentary behaviour in the last decade, promoting $\mathrm{AC}$ has been becoming a major topic which is an integral part of international initiatives aimed at increasing the level of PA within the population (4-6).

However, a number of European studies indicate that international trends in childhood overweight and obesity in many countries across Europe are still increasing (7-9). Together, reduced levels of PA are one of the factors influencing an increased prevalence of overweight and obesity among children $(10,11)$.
Strategies to increase PA, such as promoting active school travel, are important $(2,4,7)$. Concurrently, a large body of research has indicated that $\mathrm{AC}$ plays an important role in increasing the overall level of PA in children and youth $(4,12-15)$, that the promotion of AC should focus on children who spend too much time using a computer, and that attention should also be drawn to safety concerns associated with AC to and from school $(12,16)$. Furthermore, AC is also perceived as an easy and effective tool to increase the level of daily physical activity on school days, and, therefore, to enhance fitness (17), which is a marker of health in young people $(18,19)$.

Despite the potential health benefits of AC, studies from Switzerland, Canada, Australia, the United States, the United Kingdom, the Netherlands, and Brazil have reported declining proportions of children walking and cycling to school in recent decades $(7,14,20-25)$.

Moreover, it is expected that changes in modes of transport will be different in countries where cycling is much more common (e.g. the Netherlands, Denmark, Germany) $(24,26,27)$.

Dygryn et al. (28) confirmed the findings of previous international studies about decreasing levels of AC among children of school age in the Czech Republic between 2001 and 2011 and 
emphasizes the increasing number of adolescents using passive modes of transportation to school (city transport, bus, and as a car passenger).

In recent research a wide spectrum of correlates for AC has been identified. It includes family and household characteristics, which have been identified as correlates of walking or cycling to school in Australian and US studies. Having no adult at home after school was associated with a greater likelihood of walking or cycling (29-31), and children and adolescents in households with no vehicles were more likely to walk or cycle to school (32). Concurrently, another important factor influencing AC is associated with the characteristics of the building environment on the way to school (the presence of pavements, traffic safety, and the number of roads to cross) and may influence how parents choose to have their children commute from home to school (33, 34). Moreover, the level of AC in school-aged children can be influenced by the location of the school and distance from the place of residence $(12,20,28)$. These findings are important for policymakers aiming to maximize the use of active forms of transport (e.g. for public health reasons) or to minimize car use (e.g. for environmental or congestion reasons) (35).

The aim of this study is to investigate trends in AC to school among Czech girls and boys aged 11-15 years from 2006 to 2014 , using data from the cross-national Health Behaviour in Schoolaged Children (HBSC) study.

\section{MATERIALS AND METHODS}

The present survey follows the international HBSC study and its methodology is identical (10). The HBSC is performed in cooperation with the World Health Organization and is an international school-based study focusing on the health and health behaviour of 11-, 13-, and 15-year-old schoolchildren in their respective social environments. School-based anonymous surveys were conducted during April, May, and June in 2006, 2010 and 2014 and were approved by the Ethical Committee of the Faculty of Physical Culture. The completion of the HBSC questionnaire by children was voluntary; no incentives were provided in return for participation. All the Czech schools participating in the study had a general permission granted by all parents at the beginning of the school year. The final data check was performed by the International Databank, University of Bergen, Norway, in compliance with the international HBSC standards (36).

\section{Sample}

For the purposes of this article data from 12,273 respondents was analyzed, out of whom 5,992 (48.8\%) were boys and 6,281 (51.2\%) girls. In 2006, the final dataset for this analysis included 4,029 children $(50.3 \%$ of boys) (response rate $88.5 \%$ ). In 2010 , a total of 3,956 children ( $47.7 \%$ of boys) were eligible for the analysis (response rate $89.2 \%$ ). The latest survey in 2014 included 4,288 children ( $48.4 \%$ of boys) for the analysis (response rate was $89.2 \%)$. Age categories were governed by the HBSC protocol: the 11-year-old age category included children aged 11.0-11.99 years, the 13-year-old age category included children aged 13.0-13.99 years, and children aged 15.0-15.99 years were regarded as the 15 -year-old age category (37).

\section{Survey Items}

\section{Assessment of Active Commuting to and from School}

In 2006, 2010 and 2014 two items related to AC on school days were used. The adolescents were asked the following questions concerning mode of transport to and from school - the respondents were asked to indicate in the questionnaires their usual mode of transport to and from school during the current week. The question was: "What is your main mode of transport to school and from school on a typical day?" Five response options were available for either direction: walking, cycling, bus/train/tram/underground (here called 'public transport', including school bus), car/motorcycle/moped, and other. The respondents could select only one type of transport for each direction. AC is operationalized as reporting either walking or cycling to school, from school, or both.

\section{Statistical Analyses}

All the data was analyzed using IBM SPSS (Version 22 for Windows; IBM, Armonk, NY, USA) for all the schools together because the TwoStep cluster analysis found no indicator for clustering by school. To determine the trends logistic regression analysis (Enter method) was used with a dependent variable $\mathrm{AC}$ to and from school and an independent categorical variable, which was the year that the survey was completed, i.e. the years 2006, 2010 and 2014. To describe differences in AC by gender and age categories in more detail we applied an Analysis of Variance approach with a dependent variable - AC to school and independent variables gender (boys, girls) and age categories (11, 13 , and 15 years old).

\section{RESULTS}

Table 1 presents the proportions of school-aged children using $\mathrm{AC}$ to and from school by age and gender. The trends over the 2006-2014 period were, however, generally similar for adolescents of all ages. Across the whole sample, there was a decrease in the use of AC between 2006 and 2014. The largest differences were reported between the two measurement points 2006 and 2014, when there was a significant decrease in the use of active commuting among 13-year-old boys and girls (boys $-21.7 \%$, girls $-23.0 \%$ ). AC to and from school was the most common mode of transportation for 11-year-old boys and girls of the same age in 2014. The lowest rate of prevalence of AC was observed among 13-year-old girls in 2014.

The percentages of commuting modes to school in the study population by measurement point for the whole sample and for the boys and girls are shown in Figures 1 and 2. These figures also present the specific proportion of children who walked, cycled, used public transport, or rode in a car. The proportion of children actively commuting (walking and cycling) to school significantly decreased from $74.3 \%$ in 2006 to $53.4 \%$ in 2014 . Walking to school declined from $67.5 \%$ in 2006 to $50.8 \%$ in 2014 and the use of public transport increased among the girls. Concurrently, some increase was observed for using public transportation and the percentage of girls riding in a car or on a motorbike is also increasing. Equally, the use of cars or motorbikes increased from $5.7 \%$ to $7.7 \%$ and then to $11.9 \%$ at the 2006,2010 and 2014 
Table 1. Prevalence and trends of active commuting (walking, cycling or both) to and from school among Czech children between the years 2006 and $2014(N=12,273)$

\begin{tabular}{|c|c|c|c|c|c|c|c|c|c|}
\hline \multirow{3}{*}{ Variable } & \multirow{3}{*}{$\begin{array}{c}2006 \\
\%\end{array}$} & \multirow{3}{*}{$\begin{array}{c}2010 \\
\%\end{array}$} & \multirow{3}{*}{$\begin{array}{c}2014 \\
\%\end{array}$} & \multicolumn{3}{|c|}{2010 vs. 2006} & \multicolumn{3}{|c|}{2014 vs. 2006} \\
\hline & & & & \multirow{2}{*}{ OR } & \multicolumn{2}{|c|}{$\mathrm{Cl}$} & \multirow{2}{*}{ OR } & \multicolumn{2}{|c|}{$\mathrm{Cl}$} \\
\hline & & & & & Lower & Upper & & Lower & Upper \\
\hline \multicolumn{10}{|l|}{ Boys } \\
\hline $11-11.99$ years & 71.9 & 62.9 & 58.4 & 0.67 & 0.53 & 0.84 & 0.55 & 0.44 & 0.70 \\
\hline $13-13.99$ years & 71.8 & 54.6 & 50.1 & 0.47 & 0.37 & 0.60 & 0.39 & 0.32 & 0.49 \\
\hline $15-15.99$ years & 69.5 & 58.5 & 52.5 & 0.62 & 0.49 & 0.77 & 0.48 & 0.39 & 0.60 \\
\hline \multicolumn{10}{|l|}{ Girls } \\
\hline $11-11.99$ years & 73.5 & 60.2 & 54.2 & 0.55 & 0.43 & 0.69 & 0.43 & 0.34 & 0.54 \\
\hline 13-13.99 years & 69.3 & 52.6 & 46.3 & 0.49 & 0.39 & 0.61 & 0.38 & 0.31 & 0.48 \\
\hline $15-15.99$ years & 70.1 & 54.5 & 51.4 & 0.51 & 0.41 & 0.64 & 0.45 & 0.36 & 0.56 \\
\hline
\end{tabular}

Results from logistic regression; (\%) percentage of participants who walked or cycled to and from school; OR: odds ratio (the cohort from the year 2006 is the reference group); Cl: $95 \%$ confidence interval; all ORs are at the level of statistical significance $p \leq 0.001$.

measurement points. Cycling was used very little by the girls: $2.3 \%, 0.5 \%$ and $2.0 \%$ in 2006,2010 and 2014 , respectively. The proportion of children using AC to school decreased, while the percentage of children using public transport or riding in a car increased from $28.2 \%$ in 2006 to $40.6 \%$ in 2014.

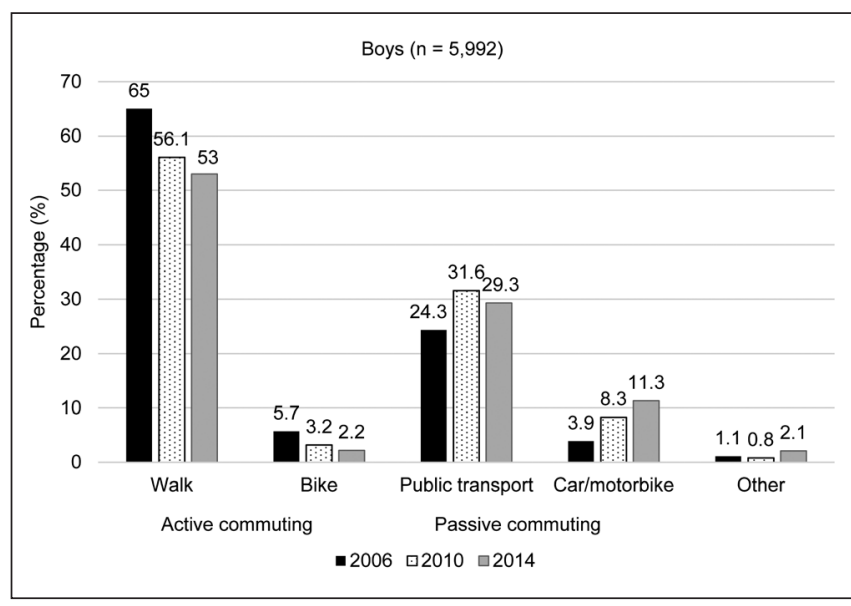

Fig. 1. Specific proportion of boys who walked, cycled, used public transport, or rode in a car/on a motorbike to school.

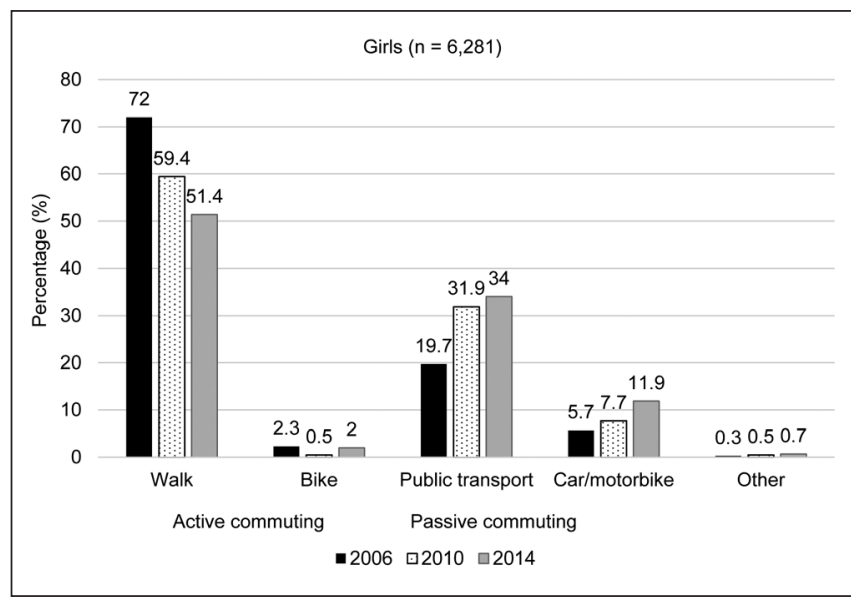

Fig. 2. Specific proportion of girls who walked, cycled, used public transport, or rode in a car/on a motorbike to school.

\section{DISCUSSION}

This study investigated trends in AC to school among Czech girls and boys aged 11-15 years from 2006 to 2014, using data from the cross-national HBSC study. We found that the use of AC (walking or cycling) by Czech schoolchildren decreased between 2006 and 2014. Concurrently, during the same time period, significantly more children used passive modes of transport. Increases were observed in the use of public transportation and riding in a car or on a motorbike as well.

Our results are in line with the findings of several previous studies focused on Czech schoolchildren $(8,28)$. The same overall decline in reported AC to school has been found in studies conducted in high-income countries such as Australia (from 57.7\% in 1971 to $25.6 \%$ in 2003) (21), Canada (from $55.7 \%$ in 1986 to $43.4 \%$ in 2006) (14), the United States (from $40.7 \%$ in 1969 to $12.9 \%$ in 2001) (32), the United Kingdom (from $82.0 \%$ in 1971 to $64.0 \%$ in 2010 ) (38), Germany (primary school children from $88.0 \%$ in 1990 to $67.0 \%$ in 2010 , and secondary school children from $42.0 \%$ in 1990 to $22.0 \%$ in 2010 ) (38), and Switzerland (from $78.4 \%$ in 1994 to $71.4 \%$ in 2005 ) (7).

However, although the overall reported levels of $\mathrm{AC}$ of Czech schoolchildren are still high, the decline is greater than in observed in other countries $(14,21,32,38)$. The decrease was mainly due to a reduction in walking to school, and in a less pronounced way to a reduction of bike use over time. The decrease in walking and cycling to school is also influenced by the location of the school and its distance from the place of residence (12), as well as the actual traffic safety conditions around the school location (39).

Nevertheless, walking was the most common mode of AC on the way to school. These results were consistent with other studies $(24,41)$.

There has been an increase in the use of public transport or riding in a car/on a motorbike, which accounted for the decrease in the proportion of children walking or cycling to school. The reasons for this difference would be interesting to explore in terms of different environmental factors which influenced the trend of bike and car use over time $(27,41)$. Moreover, future research should continue to analyze the influences of the many other correlates of school travel (household and environmental 
characteristics, social support, travel distance and/or time, safety, traffic) that were not part of our study.

There are few differences between boys and girls in the modes used to travel to school and their preferred mode. On the journey to school more boys than girls cycled. However, our findings were consistent with those of other studies $(35,42)$ where gender effects were identified. Johansson et al. (43) also found that Swedish boys were significantly more likely to cycle than girls. On the other hand, other published studies $(12,15,28)$ show no gender differences in AC to school. However, more data is needed in order to better understand these findings and future studies should continue to deeply analyze gender differences in AC among school-aged children and bring better understanding of the changing patterns of this behaviour over time.

\section{Strengths and Limitations}

This study has several important strengths. The most important strength is the methodology of the international HBSC study that was used in our study, which has managed to adapt to developments in the research areas within and around public health and policy (44). For all the surveys that are conducted, a standardized research protocol providing a theoretical framework for the research topics and data collection and analysis procedures has been developed (36). On the basis of this protocol, the metrics used in this paper were included in 2006, 2010 and 2014, adding to the quality of the data used for analyzing time trends. In addition, the regional Central European comparisons provide baseline data which could be useful for the future investigation of health-related behaviour.

On the other hand, the study also has some limitations. One limitation of this study is that it is based on self-reported data, so the reported prevalence may be biased as a result of over- or underreporting. Additionally, while dichotomous classifications of the preferred way of commuting might be considered somewhat crude, such classification is less vulnerable to reporting errors. Another limitation may lie in the reporting of honest responses. However, all the participants were assured of the anonymity of the study and that neither their parents nor their teacher would find out about their individual answers or get any access to the study data. Second, the descriptive nature of this paper only refers to the prevalence of different means of transportation to school, and does not take into account important correlates of AC found in previous research. Thus, the results of this study cannot contribute to the understanding of why fewer children walk or cycle to school. The results of this study are, however, in line with previous research and add knowledge about the declining trends of this health-related behaviour. Finally, it should be emphasized that the findings presented here refer to cross-sectional trends that may not accurately reflect the findings of true longitudinal study approaches.

\section{CONCLUSIONS}

AC to school among Czech children of school age decreased sharply from 2006 to 2014. This trend represents a critical loss of everyday physical activity for young people and could be part of the comprehensive explanation of the increase in childhood obesity in the Czech Republic. PA interventions for youth should encourage participation in AC to school. As highlighted by previous research, there is a need for stakeholders to work together for a successful initiative that promotes AC in children with the aim of reducing the environmental and structural barriers to the adoption of this behaviour among school-aged children.

\section{Acknowledgements}

This work was supported by the research grant of the Czech Science Foundation Reg. No. 17-12579S and by the Czech Ministry of Education, Youth and Sports (MEYS) under Contracts No. LG 14043.

\section{Conflict of Interests}

None declared

\section{REFERENCES}

1. Sallis J, Frank L, Saelens B, Kraft M. Active transportation and physical activity: opportunities for collaboration on transportation and public health research. Transp Res Part A Policy Pract. 2004;38(4):249-68.

2. Andersen LB. Active commuting: an easy and effective way to improve health. Lancet Diabetes Endocrinol. 2016 May;4(5):381-2.

3. Owen N, Humpel N, Leslie E, Bauman A, Sallis JF. Understanding environmental influences on walking; Review and research agenda. Am J Prev Med. 2004 Jul;27(1):67-76.

4. Mendoza JA, Watson K, Nguyen N, Cerin E, Baranowski T, Nicklas TA. Active commuting to school and association with physical activity and adiposity among US youth. J Phys Act Health. 2011 May;8(4):488-95.

5. Ng SW, Popkin BM. Time use and physical activity: a shift away from movement across the globe. Obes Rev. 2012 Aug;13(8):659-80.

6. Kalman M, Inchley J, Sigmundova D, Iannotti RJ, Tynjälä JA, Hamrik $\mathrm{Z}$, et al. Secular trends in moderate-to-vigorous physical activity in 32 countries from 2002 to 2010: a cross-national perspective. Eur J Public Health. 2015 Apr;25 Suppl 2:37-40. doi: 10.1093/eurpub/ckv024.

7. Grize L, Bringolf-Isler B, Martin E, Braun-Fahrländer C. Trend in active transportation to school among Swiss school children and its associated factors: three cross-sectional surveys 1994, 2000 and 2005. Int J Behav Nutr Phys Act. 2010 Apr 15;7:28. doi: 10.1186/1479-5868-7-28.

8. Sigmundová D, Sigmund E, Hamrik Z, Kalman M. Trends of overweight and obesity, physical activity and sedentary behaviour in Czech schoolchildren: HBSC study. Eur J Public Health. 2014 Apr;24(2):210-5.

9. Ng M, Fleming T, Robinson M, Thomson B, Graetz N, Margono C, et al. Global, regional, and national prevalence of overweight and obesity in children and adults during 1980-2013: a systematic analysis for the Global Burden of Disease Study 2013. Lancet. 2014 Aug 30;384(9945):766-81.

10. Sigmund E, Sigmundová D, Badura P, Kalman M, Hamrik Z, Pavelka J. Temporal trends in overweight and obesity, physical activity and screen time among Czech adolescents from 2002 to 2014: A National Health Behaviour in School-Aged Children Study. Int J Environ Res Public Health. 2015 Sep 18;12(9):11848-68.

11. Knai C, Suhrcke M, Lobstein T. Obesity in Eastern Europe: an overview of its health and economic implications. Econ Hum Biol. 2007 Dec;5(3):392408 .

12. Pavelka J, Sigmundová D, Hamřík Z, Kalman M. Active transport among Czech school-aged children. Acta Univ Palacki Olomuc Gymn. 2012;42(3):17-26.

13. Cozma I, Kukaswadia A, Janssen I, Craig W, Pickett W. Active transportation and bullying in Canadian schoolchildren: a cross-sectional study. BMC Public Health. 2015 Feb 7;15:99. doi: 10.1186/s12889-015-1466-2.

14. Buliung RN, Mitra R, Faulkner G. Active school transportation in the Greater Toronto Area, Canada: an exploration of trends in space and time (1986-2006). Prev Med. 2009 Jun;48(6):507-12.

15. Ostergaard L, Kolle E, Steene-Johannessen J, Anderssen SA, Andersen LB. Cross sectional analysis of the association between mode of school transportation and physical fitness in children and adolescents. Int J Behav Nutr Phys Act. 2013 Jul 17;10:91. doi: 10.1186/1479-5868-10-91.

16. Bringolf-Isler B, Grize L, Mäder U, Ruch N, Sennhauser FH, BraunFahrländer C; SCARPOL team. Personal and environmental factors associated with active commuting to school in Switzerland. Prev Med. 2008 Jan;46(1):67-73. 
17. Chillón P, Ortega FB, Ruiz JR, Veidebaum T, Oja L, Mäestu J, et al. Active commuting to school in children and adolescents: an opportunity to increase physical activity and fitness. Scand J Public Health. 2010 Dec;38(8):873-9

18. Cooper AR, Wedderkopp N, Wang H, Andersen LB, Froberg K, Page AS. Active travel to school and cardiovascular fitness in Danish children and adolescents. Med Sci Sports Exerc. 2006 Oct;38(10):1724-31.

19. van Sluijs EM, Fearne VA, Mattocks C, Riddoch C, Griffin SJ, Ness A. The contribution of active travel to children's physical activity levels: cross-sectional results from the ALSPAC study. Prev Med. 2009 Jun;48(6):519-24

20. Faulkner GE, Buliung RN, Flora PK, Fusco C. Active school transport, physical activity levels and body weight of children and youth: a systematic review. Prev Med. 2009 Jan;48(1):3-8.

21. van der Ploeg HP, Merom D, Corpuz G, Bauman AE. Trends in Australian children traveling to school 1971-2003: burning petrol or carbohydrates? Prev Med. 2008 Jan;46(1):60-2.

22. Ham SA, Macera CA, Lindley C. Trends in walking for transportation in the United States, 1995 and 2001. Prev Chronic Dis. 2005 Oct;2(4):A14.

23. Black C, Collins A, Snell M. Encouraging walking: the case of journey-to school trips in compact urban areas. Urban Stud. 2001;38(7):1121-41.

24. Dessing D, de Vries SI, Graham JM, Pierik FH. Active transport between home and school assessed with GPS: a cross-sectional study among Dutch elementary school children. BMC Public Health. 2014 Mar 5;14:227. doi: 10.1186/1471-2458-14-227.

25. De Sa TH, Garcia LMT, Claro, RM. Frequency, distribution and time trends of types of leisure-time physical activity in Brazil, 2006-2012. Int J Public Health. 2014 Dec;59(6):975-982.

26. Østergaard L, Grontved A, Borrestad LA, Froberg K, Gravesen M, Andersen LB. Cycling to school is associated with lower BMI and lower odds of being overweight or obese in a large population-based study of Danish adolescents. J Phys Act Health. 2012 Jul;9(5):617-25.

27. Richter M, Kuntsche E, De Looze M, Pförtner TK. Trends in socioeconomic inequalities in adolescent alcohol use in Germany between 1994 and 2006. Int J Public Health. 2013 Oct;58(5):777-84.

28. Dygrýn J, Mitáš J, Gába A, Rubín L, Frömel K. Changes in active commuting to school in Czech adolescents in different types of built environment across a 10-year period. Int J Environ Res Public Health. 2015 Oct 16;12(10):12988-98

29. Evenson KR, Huston SL, McMillen BJ, Bors P, Ward DS. Statewide prevalence and correlates of walking and bicycling to school. Arch Pediatr Adolesc Med. 2003 Sep;157(9):887-92.

30. Timperio A, Ball K, Salmon J, Roberts R, Giles-Corti B, Simmons D, et al. Personal, family, social, and environmental correlates of active commuting to school. Am J Prev Med. 2006 Jan;30(1):45-51
31. Babey SH, Hastert TA, Huang W, Brown ER. Sociodemographic, family, and environmental factors associated with active commuting to school among US adolescents. J Public Health Policy. 2009;30 Suppl 1:S203-20.

32. McDonald NC. Active transportation to school: trends among U.S. schoolchildren, 1969-2001. Am J Prev Med. 2007 Jun;32(6):509-16.

33. Davison KK, Werder JL, Lawson CT. Children's active commuting to school: current knowledge and future directions. Prev Chronic Dis. 2008 Jul;5(3):A100.

34. Panter JR, Jones AP, van Sluijs EM, Griffin SJ. Attitudes, social support and environmental perceptions as predictors of active commuting behaviour in school children. J Epidemiol Community Health. 2010 Jan;64(1):41-8.

35. Easton S, Ferrari E. Children's travel to school - the interaction of individual, neighbourhood and school factors. Transp Policy. 2015;44:9-18.

36. Roberts C, Freeman J, Samdal O, Schnohr CW, de Looze ME, Nic Gabhainn S, et al.; International HBSC Study Group. The Health Behaviour in School-aged Children (HBSC) study: methodological developments and current tensions. Int J Public Health. 2009 Sep;54 Suppl 2:140-50.

37. Sigmund E, Badura P, Sigmundova D, Csemy L, Kalman M. Methodological aspects of trend studies and development of the HBSC study in the Czech Republic. 2017. In Press.

38. Shaw B, Watson B, Frauendienst B, Redecker A, Jones T, Hillman M. Children's independent mobility: a comparative study in England and Germany (1971-2010). London: Policy Studies Institute; 2012.

39. Rojas Lopez MC, Wong YD. Children's active trips to school: a review and analysis. Int J Urb Sustain Dev Plann. 2017;9(1):79-95.

40. Bere E, Oenema A, Prins RG, Seiler S, Brug J. Longitudinal associations between cycling to school and weight status. Int J Pediatr Obes. 2011 Aug;6(3-4):182-7.

41. Gropp K, Janssen I, Pickett W. Active transportation to school in Canadian youth: should injury be a concern? Inj Prev. 2013 Feb;19(1):64-7.

42. Stewart O. Findings from research on active transportation to schoo and implications for safe routes to school programs. J Plan Lit. 2011;26(2):127-50.

43. Johansson K, Laflamme L, Hasselberg M. Active commuting to and from school among Swedish children - a national and regional study. Eur J Public Health. 2012 Apr;22(2):209-14.

44. Brindova D, Pavelka J, Ševčikova A, Žežula I, van Dijk JP, Reijneveld SA, et al. How parents can affect excessive spending of time on screen-based activities. BMC Public Health. 2014 Dec 12;14:1261. doi: 10.1186/14712458-14-1261

Received March 9, 2017

Accepted in revised form June 19, 2017 